This item was submitted to Loughborough's Research Repository by the author.

Items in Figshare are protected by copyright, with all rights reserved, unless otherwise indicated.

\title{
Design and analysis of a novel tri-band flower-shaped planar antenna for GPS and WiMAX applications
}

PLEASE CITE THE PUBLISHED VERSION

https://doi.org/10.1080/09205071.2017.1330160

\section{PUBLISHER}

(c) Taylor \& Francis

\section{VERSION}

AM (Accepted Manuscript)

\section{PUBLISHER STATEMENT}

This work is made available according to the conditions of the Creative Commons Attribution-NonCommercialNoDerivatives 4.0 International (CC BY-NC-ND 4.0) licence. Full details of this licence are available at: https://creativecommons.org/licenses/by-nc-nd/4.0/

\section{LICENCE}

CC BY-NC-ND 4.0

\section{REPOSITORY RECORD}

Ullah, Sadiq, Farooq Faisal, Ashfaq Ahmad, Usman Ali, Farooq A. Tahir, and James A. Flint. 2019. "Design and Analysis of a Novel Tri-band Flower-shaped Planar Antenna for GPS and Wimax Applications". figshare. https://hdl.handle.net/2134/24907. 


\title{
Design and Analysis of a Novel Tri-band Flower-shaped Planar Antenna for GPS and WiMAX Applications
}

\begin{abstract}
This paper presents the design of a tri-band flower-shaped planar monopole antenna operating at three frequencies i.e. $1.576 \mathrm{GHz}$ (GPS), $2.668 \mathrm{GHz}$ and 3.636 GHz (Mobile WiMAX). The radiating element of the antenna is backed by a $1.6 \mathrm{~mm}$ thicker FR-4 substrate having a dielectric constant of 4.3. The substrate is backed by a truncated ground plane. The antenna is fed through a $50 \Omega$ microstrip line. The flower shape of the radiating element is derived from the basic circular shape by introducing in it rounded slots of various radii. The upper part of the antenna is flower-shaped while the lower part comprises a microstrip feed line and two branches, each having two 'leaves' at the end. The leaves and branches contribute in the impedance matching of the lower $(1.576 \mathrm{GHz})$ and middle $(2.668 \mathrm{GHz})$ frequency bands. The antenna gives an acceptable simulated efficiency $>70 \%$ in the three frequency bands. Suitable gains of 1.63, 2.59 and 3.23dB are obtained at $1.576 \mathrm{GHz}, 2.668 \mathrm{GHz}$ and $3.636 \mathrm{GHz}$, respectively. The antenna matched with a VSWR $<1.2$ in the three frequency bands. The prototype of the antenna is fabricated and tested in the laboratory, and good agreement in simulated and measured results is achieved. The proposed design is a visually appealing and may find uses as an external antenna in GPS and WiMAX applications.
\end{abstract}

Keywords: tri-band; monopole; GPS; WiMAX

Subject classification codes: EL5, EL7, EL00, EL2

\section{Introduction}

Antennas capable of operating at more than one resonant frequencies are called multiband antennas and are used as a substitute to multiple antennas in portable devices. With the explosive advancement in modern communication systems, there is an emergent demand for this class of antennas, capable of operating in dual- or multi bands [1-3]: i.e. GSM (890-960 MHz and 1710-1990MHz); UMTS (1900-2200 MHz and 2500-2700 MHz); Wi-Fi)/WLAN (2400-2500 MHz and 5100-5800 MHz); GPS (1.559 - 1.61 GHz) and WiMAX (3.3-3.8 GHz, 5.1-5.8 GHz) bands. 
In wireless communication devices, the use of multiband antennas is usually preferred to the use of multiple single-band antennas due to their smaller footprint and the ease of connecting the feed network. Multiband functionality can be achieved by taking a conventional microstrip patch antenna and modifying it by making slots or cuts in the radiating element. There are numerous methods of modifying the shape, which seem attractive but microstrip patch antennas are inherently narrow band devices with fractional bandwidths of only a few percent. The monopole antenna is another option and has attracted the attention of researchers due to its wide bandwidth, outstanding efficiency, small size, simple geometry and ease of fabrication. Planar monopole antennas are described extensively in the literature and are characterised by their low manufacturing cost, small size, and favourable radiation characteristics.

To design compact and multi-band antennas for various wireless applications, researchers have used different geometrical shapes for the radiating element, for instance: 7-shaped [4], P-shaped [5], F-shaped [6], L-shaped [7], G-shaped [8], LVshaped [9], T-shaped [10], S-shaped [11], polygon [12], fractal [13], Rhomb [14], Hook [15], circular disk [16, 17], flower [18], etc.. However, these antennas are primarily aimed for WLAN applications. Monopole antennas for WiMAX and WLAN bands are reported in [19-24]. Multi-band antennas for GPS, WLAN and WiMAX applications are also published [25, 26]. In [25] the multiband characteristics are achieved by cutting Lshape slots in the radiating element. Due to the less lossy substrate material used in its design, this antenna gives adequate gain of $1.81 \mathrm{~dB}$ at $1.6 \mathrm{GHz}, 3.52 \mathrm{~dB}$ at $3.5 \mathrm{GHz}$ and 4.36 $\mathrm{dB}$ at $5.5 \mathrm{GHz}$, respectively. The antenna in [26] can generate GPS/WLAN/WiMAX frequency bands with satisfactory gain of $1.4 \mathrm{~dB}, 2.5 \mathrm{~dB}, 3.7 \mathrm{~dB}$ and $4.8 \mathrm{~dB}$ across $1.58 \mathrm{GHz}, 2.45 \mathrm{GHz}, 3.45 \mathrm{GHz}, 5.4 \mathrm{GHz}$ frequency bands, respectively. The antenna in [27] presents a relatively compact $\left(40 \times 20 \times 1.6 \mathrm{~mm}^{3}\right) \mathrm{F}$ - 
shaped quad-band monopole antenna for GPS/ WLAN/WiMAX systems. The average gain of this antenna significantly low (i.e. $0.35 \mathrm{~dB}$ ) in the GPS band (1.54-1.61). The author of this article also referred to other well-known methodologies used for designing multiband monopole antennas, i.e. embedded slots, adding parasitic radiating branches, loading artificial structures such as split ring resonators or complementary split ring resonators. A triple band antenna presented in [28] gives an optimum gain of $3.55 \mathrm{~dB}, 3.93 \mathrm{~dB}$ and $5.02 \mathrm{~dB}$ in the GPS, WLAN and WiMAX frequency bands, respectively. In this work a complex arrangement of rectangular slots, E- and inverted T-shaped stubs, generate these frequency bands. The gain response of this antenna is relatively better due to the low-loss substrate, and overall size of the antenna (55 x 45 $\left.\mathrm{mm}^{2}\right)$.

This paper considers a monopole antenna designed for multiband operation, which is planar and fed from a microstrip line. This antenna can be used to integrate multiple standards in single system. The antenna is designed not only to have good performance but also to be highly visible to the user of the equipment and is most suited to external mounting on the device. The antenna is efficient (>70\%), geometrically appealing, operating at GPS (1.575 GHz) and mobile WiMAX (2.6 GHz and $3.5 \mathrm{GHz})$. It has been designed using a $1.6 \mathrm{~mm}$ thicker FR4 substrate, having a relative permittivity of 4.3. The proposed antenna offers sufficient bandwidth (21 -98 MHz) in the desired frequency bands. The bandwidth requirements for the upper GPS L band are 1559 to $1610 \mathrm{MHz}$ ), which covers the GPS L1, Galileo E1 and GLONASS G1. The proposed antenna provides a $21.1 \mathrm{MHz}(1.565-1.5863 \mathrm{GHz})$ bandwidth for GPS (L1) applications. The channel bandwidth requirements for WiMAX as per European Standards is $20 \mathrm{MHz}$; The WiMAX applications operate in the licensed spectrum of 3.3 to $3.8 \mathrm{GHz}$. It also operates in the unlicensed spectrum of 5.1 to $5.8 \mathrm{GHz}$. The 
bandwidth of the proposed antenna in the WiMAX band (3.5 GHz) is $99 \mathrm{MHz}$ (3.5863$3.6843 \mathrm{GHz})$.

The antenna is simulated in CST Microwave Studio. Truncated ground plane is used to achieve multi-resonance modes at the desired frequencies. Various circular slots are created in the radiating part to achieve resonances at desired frequency bands (GPS and Mobile WiMAX). A detailed parametric study is carried out in this paper to observe the effect of changing dimensions of cuts and slots in the radiating patch.

The rest of the paper is organized as follows: Design methodology of the proposed antenna is explained in Section 2. The parametric analysis is elaborated in Section 3. The simulated and measured results are discussed in Section 4. Section 5 concludes this research and gives recommendations for future work.

\section{Design Methodology}

The geometrical model of the proposed flower-shaped monopole antenna is shown in Figure 1. The antenna uses a $1.6 \mathrm{~mm}$ thicker FR4 substrate, having a relative permittivity of 4.3. The antenna is backed by a semi-circular truncated copper ground plane. The ground plane and radiating patch are made of $0.035 \mathrm{~mm}$ thick copper sheet. The overall size of the antenna is $56 \times 59 \times 1.6 \mathrm{~mm}^{3}$. The flower-shaped patch consists of two parts: The flower shaped upper part which is the main radiating structure of this monopole antenna, the lower part consists of two identical branches with 'leaves', which aids in generating the lower and middle frequency bands. The dimensions of the circular slots and cuts within the radiating structure of the proposed antenna are chosen after a detailed parametric analysis in order to fine tune the targeted resonant frequencies to their standard frequency bands (i.e. GPS and Mobile WiMAX). The

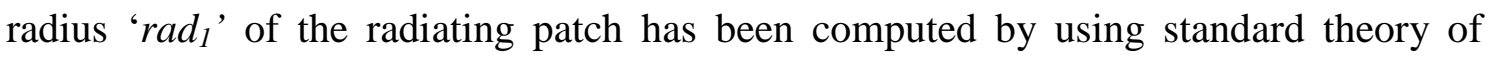
circular patch antenna [29], i.e. 


$$
\begin{aligned}
& \operatorname{rad}_{1}=\frac{F}{\left\{1+\frac{2 h}{\pi \epsilon_{r} F}\left[\ln \left(\frac{\pi F}{2 h}\right)+1.7726\right]\right\}^{1 / 2}} \\
& F=\frac{8.791 \times 10^{9}}{\mathrm{f}_{\mathrm{r} \sqrt{\epsilon_{\mathrm{r}}}}}
\end{aligned}
$$

Where $h$ is the thickness of the substrate, $\varepsilon_{r}$ is the relative permittivity of the substrate and $f_{r}$ is the resonance frequency. $F$ is an empirically derived fraction, which is inversely proportional to the resonant frequency. It controls the radius of the circular patch antenna. In the present example, we use a value of $\operatorname{rad}_{1}=15 \mathrm{~mm}$.

Figure 2 illustrates the steps to obtain the proposed flower-shaped monopole antenna. The new antenna shape can be clearly seen to be a modified version of the circular patch antenna. The modifications introduced take the form of circular and triangular slots and cuts of different sizes and are chosen to make the antenna more visually appealing, but at the same time bring in new degrees of freedom in terms of adjusting its performance parameters. The s-parameters for these design steps are compared in Figure 2b, which shows how a viable antenna without modification gives satisfactory $-10 \mathrm{~dB}$ bandwidth for the lower frequency band $(1.576 \mathrm{GHz})$ in the first step and the successive modifications improve performance in the other bands. The plots support the view that the modification to the 'flower' part of the antenna is chiefly responsible for the mid band and the 'leaf' part for the upper band. The reason why this is so may not be immediately apparent, however examination of the surface currents will be discussed in the next section and the reasons why this takes place will be explained.

The antenna is fed via a $50 \Omega$ microstrip line of width $w_{f}$. Table 1 lists various dimensions of the proposed antenna. 


\section{Parametric Analysis}

This section outlines the parametric analysis of the antenna by varying the i) radius of two leaves $\left(\mathrm{rad}_{2}\right)$, ii) radius of the central circular slot $\left(\mathrm{rad}_{3}\right)$ and iii) radius of the semicircular slots $\left(\mathrm{rad}_{4}\right)$.

\subsection{Varying rad $_{2}$}

Figure 3 and Table 2 present the behaviour of the antenna in terms of reflection coefficient as a function of $\mathrm{rad}_{2}$. This graph clearly demonstrates that when $\mathrm{rad}_{2}$ is less than $5 \mathrm{~mm}$, the three resonant frequencies shifts slightly towards the right. It is also observed that the reflection coefficient drops, in the $1.576 \mathrm{GHz}$ and $2.668 \mathrm{GHz}$ frequency bands, below the $-10 \mathrm{~dB}$ threshold of input impedance bandwidth. When $\mathrm{rad}_{2}$ is increased from $5 \mathrm{~mm}$, similar reduction in $-10 \mathrm{~dB}$ bandwidth occurs in these frequency bands. The bands also shift towards the left, relative to the curve for $\operatorname{rad}_{2}=5 \mathrm{~mm}$ (reference). It is worth noting that variations in $\mathrm{rad}_{2}$ have minimal effects on the upper frequency band $(3.6 \mathrm{GHz})$ in terms of resonant frequency shift/drift and the $10 \mathrm{~dB}$ bandwidth. The present study suggests that $\mathrm{rad}_{2}=5 \mathrm{~mm}$, is an optimum choice, for the antenna to operate satisfactorily, giving a $-10 \mathrm{~dB}$ bandwidth $(>70 \mathrm{MHz})$ in the 2.668 and 3.6 GHz bands.

\subsection{Varying rad $_{3}$}

Variations in the performance of antenna in terms of the reflection coefficient and in the positions of the resonant frequency bands as a function of the radius of the central circular slot $\left(\mathrm{rad}_{3}\right)$, are shown in Figure 4 and Table 3. It is apparent from the graph that when $3 \mathrm{~mm} \leq \operatorname{rad}_{3} \leq 7 \mathrm{~mm}$, there is minimal change in antenna behaviour in the three frequency bands. However, when $\mathrm{rad}_{3}=8 \mathrm{~mm}$, the three frequencies shifts towards the 
left, relative to $\operatorname{rad}_{3}=5 \mathrm{~mm}$. All the bands are adequately matched if $\operatorname{rad}_{3}$ is fixed to 5 $\mathrm{mm}$ and hence this is chosen.

\subsection{Varying $\mathrm{rad}_{4}$}

The lower frequency band $(1.567 \mathrm{GHz})$ and the upper frequency band (3.6 GHz) shift towards the right side while the middle band $(2.668 \mathrm{GHz})$ shifts towards the left side by lowering the value of $\mathrm{rad}_{4}(<6.5 \mathrm{~mm})$. In general, degradation in reflection coefficient is observed for all three frequency bands as shown in Figure 5 and Table 4.

By increasing $\operatorname{rad}_{4}(>6.5 \mathrm{~mm})$, the lower and upper frequency bands shift towards the left side while the middle frequency band shifts towards the right side. In general, reduction in reflection coefficient is observed for all three frequency bands. It is worth noting that when $\mathrm{rad}_{4}=8.5 \mathrm{~mm}$, the proposed antenna becomes single band operating at $2.578 \mathrm{GHz}$ with a reflection coefficient of -30.31 . For $\operatorname{rad}_{4}=9.5 \mathrm{~mm}$, the antenna works in triple band mode but the $-10 \mathrm{~dB}$ bandwidth is drastically degraded in the upper frequency band $(3.636 \mathrm{GHz})$. For these larger values of $\mathrm{rad}_{4}$, more than half of the radius of the main patch has been removed, and so it may suggest that it is inadvisable to select $\mathrm{rad}_{4}>\mathrm{rad}_{1} / 2$. Here $\mathrm{rad}_{4}=6.5 \mathrm{~mm}$ has been selected in order to obtain the desired GPS and Mobile WiMAX band performance.

\subsection{Varying $l_{1}$}

As shown in Figure 6 and Table 5, the three resonant frequency bands shift towards the right side for $l_{1}<5 \mathrm{~mm}$ and shift towards the left side if $l_{1}>5 \mathrm{~mm}$. The minimum value of reflection coefficient also fluctuates around $-10 \mathrm{~dB}$ in these frequency bands for $l_{1}$ $<5 \mathrm{~mm}$ and $l_{1}>5 \mathrm{~mm}$. However, it is observed that $l_{1}=5 \mathrm{~mm}$ is most suitable option for tuning the desired frequency bands to optimal $-10 \mathrm{~dB}$ bandwidth. 


\section{Results and Discussions}

This section presents the comparison of simulated and measured results of the proposed flower-shaped monopole antenna. The snapshot of the fabricated flower shape antenna and the associated measurement setup at National University of Science and Technology (NUST) are shown in Figure 7 and 8 respectively. The proposed antenna is fixed on the positioner in the far-field zone of a broadband horn antenna (probe).

\subsection{Reflection Coefficient}

The proposed flower-shaped monopole antenna resonates at three frequencies, 1.576 GHz, 2.668 GHz and $3.636 \mathrm{GHz}$. The bandwidths achieved at these frequencies are 21.1MHz, 72.2 $\mathrm{MHz}$ and 98.9 $\mathrm{MHz}$ respectively. The lowest values of reflection coefficients are $-29.691 \mathrm{~dB},-22.084 \mathrm{~dB}$ and $-26.765 \mathrm{~dB}$ at the three frequencies respectively (Figure 9). A good agreement between the simulated and measured reflection coefficients is observed for the lower $(1.576 \mathrm{GHz})$ and middle (2.668 GHz) frequency bands. There is a slight shift towards the right, in the measured response for the upper (3.636) frequency band, however the antenna remains tuned within the $-10 \mathrm{~dB}$ bandwidth in this band.

\subsection{Radiation Patterns}

Figure 10 demonstrates the comparison of simulated and measured gain patterns of the proposed flower-shaped antenna, in the $E$ and $H$ planes, at the three desired resonance frequencies. The maximum gain achieved at $1.576 \mathrm{GHz}, 2.668 \mathrm{GHz}$ and $3.636 \mathrm{GHz}$ is 2.26, 3.48 and $4.5 \mathrm{~dB}$ respectively. The shape of the radiation pattern is 'figure of eight' in the $E$-plane and partially omni directional in the $H$-plane. Table 6 summarizes the overall performance of the proposed flower-shaped antenna at the three frequency bands. 


\subsection{Surface Fields}

The snapshots of the surface $E$-fields of the flower shape antenna derived from the simulation study are illustrated in Figure 11. It is evident from the plots that the effective resonant length of the antenna is inversely proportional to the given frequency band. The entire radiating element (flower) radiates at the lowest frequency (1.576 GHz) as shown in Figure 11a. A small segment of the upper and lower parts of the flower radiates at the middle frequency $(2.668 \mathrm{GHz})$. The left and right side portions (Figure 11c) of the antenna radiates predominately at the upper frequency band (3.636 GHz). The effective resonant lengths of the antenna responsible for radiation are encircled in Figure 11.

For further clarity the snapshots of the surface currents, recorded at the three frequency bands are illustrated in Figure 12. Figure 12a shows that the step of the flower and branches have the highest current density which contribute to generate the lowest resonant frequency band $(1.576 \mathrm{GHz})$. The current density is higher at the edges of the flower part and the truncated ground plane as well as the branches which helps to generate the middle frequency band $(2.668 \mathrm{GHz})$ as shown in Figure 12b. In Figure 12c the current density is prominent at the lower part of the flower which adds in generating the upper frequency band (3.636 GHz).

\section{Conclusion}

A novel triple-band flower-shaped monopole antenna which is visuallyappealing is designed and analyzed in this paper. In order to get optimal results, a detailed parametric study has been conducted by varying the radii and length of various parts of the radiating element. The antenna works at GPS (1.575 GHz) and mobile WiMAX (2.5 GHz and 3.5 GHz) frequency bands. The proposed antenna is printed on a lossy FR-4 substrate and measurements were conducted in an anechoic chamber 
facility. The simulated and measured results were found in good agreement. The antenna radiates efficiency ( $>70 \%$ ) in the three frequency bands and can be used as an external antenna in wireless applications (GPS and Mobile WiMAX). The antenna is properly matched with a VSWR $<1.2$ in all bands.

References:

1. Z. N. Chen, Antennas for Portable Devices. Hoboken, NJ: Wiley, 2007.

2. Secmen M. Multiband and wideband antennas for mobile communication systems. INTECH Open Access Publisher; 2011.

3. Moosazadeh M, Esmati Z. Small Planar Dual Antenna for Wireless Local Area Network Applications Using Slotted Conductor Backed Plane. Microwave and Optical Technology Letters. 2013 Oct 1;55(10):2380-3.

4. Shah SA, Khan MF, Ullah S, Flint JA. Design of a multi-band frequency reconfigurable planar monopole antenna using truncated ground plane for Wi-Fi, WLAN and WiMAX applications. In Open Source Systems and Technologies (ICOSST), 2014 International Conference on 2014 Dec 18 (pp. 151-155). IEEE.

5. Yang $\mathrm{H}$, Yan S. A novel $\mathrm{P}$ F\$Daped printed mo applications. Microwave and Optical Technology Letters. 2009 Feb 1;51(2):554-6.

6. Yeh SH, Wong KL. Integrated F-shaped monopole antenna for $2.4 / 5.2 \mathrm{GHz}$ dual band operation. Microwave and optical technology letters. 2002 Jul 5;34(1):24-6.

7. Lin YF, Chen HD, Chen HM. A dual band printed L-shaped monopole for WLAN applications. Microwave and Optical Technology Letters. 2003 May 5;37(3):214-6.

8. Pan CY, Huang $\mathrm{CH}$, Horng TS. A new printed G-shaped monopole antenna for dual band WLAN applications. Microwave and Optical Technology Letters. 2005 May 20;45(4):295-7.

9. Tang IT, Li CM, Hung CH. Octa-band LV-shape CPW-fed monopole antenna. Journal of Electromagnetic Waves and Applications. 2011 Jan 1;25(10):1471-80. 
10. Kuo YL, Wong KL. Printed double-T monopole antenna for 2.4/5.2 GHz dual-band WLAN operations. IEEE Transactions on Antennas and Propagation. 2003 Sep;51(9):2187-92.

11. Liu, W. C., W. R. Chen, and C. M. Wu, "Printed double S shaped monopole antenna for wideband and multiband operation of wireless communication,” IEE Proc. Microwave Antennas Propag., Vol. 151, No. 6, 473-476, 2004.

12. Sundarsingh EF, Velan S, Kanagasabai M, Sarma AK, Raviteja C, Alsath MG. Polygon-shaped slotted dual-band antenna for wearable applications. IEEE Antennas and Wireless Propagation Letters. 2014;13:611-4.

13. Lizzi L, Massa A. Dual-band printed fractal monopole antenna for LTE applications. IEEE Antennas and Wireless Propagation Letters. 2011;10:760-3.

14. Chen WS, Yu YH. The design of printed rhomb-shaped antenna with slits for WiMAX systems. Microwave and Optical Technology Letters. 2007 Oct 1;49(10):2503-8.

15. Lee CH, Park SO. A compact printed hook-shaped monopole antenna for $2.4 / 5 \mathrm{GHz}$ WLAN applications. Microwave and optical technology letters. 2006 Feb 1;48(2):327-9.

16. Antoniades MA, Eleftheriades GV. A compact multiband monopole antenna with a defected ground plane. IEEE Antennas and wireless propagation letters. 2008;7:6525.

17. Zhu Y, Li MQ, He HQ. A compact dual-band monopole antenna for 4G LTE and WIFI utilizations. In Advanced Materials and Processes for RF and $\mathrm{THz}$ Applications (IMWS-AMP), 2016 IEEE MTT-S International Microwave Workshop Series on 2016 Jul 20 (pp. 1-4). IEEE.

18. Lin DB, Tang IT, Chang YY. Flower-like CPW-FED monopole antenna for quadband operation of mobile handsets. Journal of Electromagnetic Waves and Applications. 2009 Jan 1;23(17-18):2271-8.

19. He K, Wang RX, Wang YF, Sun BH. Compact tri-band claw-shaped monopole antenna for WLAN/WiMAX applications. Journal of Electromagnetic Waves and Applications. 2011 Jan 1;25(5-6):869-77.

20. Lu JH, Lee YY. Planar compact triple-band monopole antenna for IEEE $802.16 \mathrm{~m}$ WiMAX application. Journal of Electromagnetic Waves and Applications. $2013 \mathrm{Jul}$ 1;27(10):1206-19. 
21. Li CM, Wang K, Chen CK. Small tri-band monopole antenna for WiMAX/WLAN applications. Journal of Electromagnetic Waves and Applications. 2011 Jan 1;25(89):1297-307.

22. Liu WC, Wu CM, Dai Y. Design of triple-frequency microstrip-fed monopole antenna using defected ground structure. IEEE Transactions On antennas and propagation. 2011 Jul;59(7):2457-63.

23. Li Y, Yu W. A miniaturized triple band monopole antenna for WLAN and WiMAX applications. International Journal of Antennas and Propagation. 2015 Oct 1;2015: $1-5$.

24. Song Y, Jiao YC, Zhao G, Zhang FS. Multiband CPW-fed triangle-shaped monopole antenna for wireless applications. Progress In Electromagnetics Research. 2007;70:329-36.

25. Chen S, Fang M, Dong D, Han M, Liu G. Compact multiband antenna for GPS/WiMAX/WLAN applications. Microwave and Optical Technology Letters. 2015 Aug 1;57(8):1769-73.

26. Wu L, Huang J, Yuan N. Compact multiband monopole antenna for GPS/WLAN/WiMAX application. In Microwave and Millimeter Wave Technology (ICMMT), 2016 IEEE International Conference on 2016 Jun 5 (Vol. 2, pp. 618620). IEEE.

27. Ren W, Hu SW, Jiang C. An ACS-fed F-shaped monopole antenna for GPS/WLAN/WiMAX applications. International Journal of Microwave and Wireless Technologies. 2016 Oct:1-7.

28. Cao YF, Cheung SW, Yuk TI. A multiband slot antenna for GPS/WiMAX/WLAN systems. IEEE Transactions on Antennas and Propagation. 2015 Mar;63(3):952-8.

29. Balanis CA. Antenna theory: analysis and design. 4th Ed., John Wiley \& Sons, 2016. 
Table 1. Parameters of flower-shaped monopole antenna

Table 2. Summary of variations in reflection coefficient and frequency bands due to $\operatorname{rad}_{2}$

Table 3. Summary of variations in reflection coefficient and frequency bands due to $\operatorname{rad}_{3}$

Table 4. Summary of variations in reflection coefficient and frequency bands due to $\mathrm{rad}_{4}$

Table 5. Summary of variations in reflection coefficient and frequency bands due to $l_{1}$

Table 6. Summary of performance factors

Figure 1. Geometrical model of proposed flower-shaped monopole antenna

Figure 2. Geometry and reflection coefficient of the proposed flower-shaped monopole antenna (a) design steps (b) comparison of S-parameters for these design steps (c) comparison of the Sparameters of the proposed antenna with and without the branches

Figure 3. Reflection coefficient and resonant frequency variations due to $\operatorname{rad}_{2}$

Figure 4. Reflection coefficient and frequencies variations due to $\operatorname{rad}_{3}$

Figure 5. Reflection coefficient and frequency variations due to $\mathrm{rad}_{4}$

Figure 6. Variation in reflection coefficient and frequency bands due to changes in $l_{1}$

Figure 7. Fabricated flower shape antenna

Figure 8. Measurement setup in anechoic chamber (NUST, Islamabad)

Figure 9. Simulated and measured reflection coefficient

Figure 10. Comparison of simulated and measured gain

Figure 11. Surface electric field plots of the proposed antenna at various frequencies

Figure 12. Surface current plots of the proposed antenna at various frequencies 
Table 1. Parameters of flower-shaped monopole antenna

\begin{tabular}{lll}
\hline Parameter & \multicolumn{1}{c}{ Description } & Value(mm) \\
\hline$L_{s}$ & Length of substrate or ground plane & 59 \\
$W_{s}$ & Width of substrate or ground plane & 56 \\
$h$ & Thickness of substrate & 1.6 \\
$\mathrm{grad}$ & Radius of the semi-circular slot in the ground plane & 25.6 \\
$\mathrm{rad}_{1}$ & Radius of the upper flower-shaped part & 15 \\
$\mathrm{rad}_{2}$ & Radius of the lower leaf-shaped parts & 5 \\
$\mathrm{rad}_{3}$ & Radius of the slot in the centre of the upper flower-shaped part & 5 \\
$\mathrm{rad}_{4}$ & Radius of the outer slots in the upper flower-shaped part & 6.5 \\
$l_{5}$ & Outer length of the cone-shaped cut in the leaves & 1.5 \\
$l_{1}$ & Length between the upper flower-shaped and lower branches parts & 5 \\
$l_{2}$ & Length of the two branches & 4 \\
$l_{4}$ & Length of cone-shaped slots & 9 \\
$L_{f}$ & Length of the microstrip feed line & 18.5 \\
$W_{f}$ & Width of the microstrip feed line & 6 \\
$w_{1}$ & Width of the two branches & 2 \\
\hline
\end{tabular}

Table 2. Summary of variations in reflection coefficient and frequency bands due to $\mathrm{rad}_{2}$

\begin{tabular}{lllllll}
\hline $\operatorname{rad}_{2}(\mathrm{~mm})$ & $\mathrm{f}_{1}(\mathrm{GHz})$ & $\mathrm{S}_{11}$, at $\mathrm{f}_{1}$ & $\mathrm{f}_{2}(\mathrm{GHz})$ & $\mathrm{S}_{11}$, at $\mathrm{f}_{2}$ & $\mathrm{f}_{3}(\mathrm{GHz})$ & $\mathrm{S}_{11}$, at $\mathrm{f}_{3}$ \\
\hline 3 & 1.7559 & -2.706 & 2.7994 & -0.373 & 3.733 & -8.769 \\
4 & 1.6665 & -5.895 & 2.728 & -7.101 & 3.676 & -16.811 \\
5 & 1.576 & -29.691 & 2.668 & -22.084 & 3.636 & -26.765 \\
6 & 1.4964 & -2.716 & 2.643 & -10.781 & 3.601 & -41.599 \\
7 & 1.4374 & -0.995 & 2.6412 & -8.010 & 3.604 & -25.998 \\
8 & 1.3847 & -8.518 & 2.6412 & -6.652 & 3.58 & -21.889 \\
\hline
\end{tabular}

Table 3. Summary of variations in reflection coefficient and frequency bands due to $\operatorname{rad}_{3}$

\begin{tabular}{lllllll}
\hline $\operatorname{rad}_{3}(\mathrm{~mm})$ & $\mathrm{f}_{1}(\mathrm{GHz})$ & $\mathrm{S}_{11}$, at $\mathrm{f}_{1}$ & $\mathrm{f}_{2}(\mathrm{GHz})$ & $\mathrm{S}_{11}$, at $\mathrm{f}_{2}$ & $\mathrm{f}_{3}(\mathrm{GHz})$ & $\mathrm{S}_{11}$, at $\mathrm{f}_{3}$ \\
\hline 3 & 1.582 & -30.335 & 2.668 & -24.379 & 3.646 & -24.832 \\
4 & 1.576 & -30.124 & 2.6651 & -27.264 & 3.6371 & -25.018 \\
5 & 1.576 & -29.691 & 2.668 & -22.084 & 3.636 & -26.765
\end{tabular}




\begin{tabular}{lllllll}
6 & 1.567 & -40.781 & 2.6505 & -20.610 & 3.6309 & -22.974 \\
7 & 1.558 & -33.501 & 2.6381 & -16.115 & 3.6153 & -19.820 \\
8 & 1.54 & -27.053 & 2.635 & -12.630 & 3.5688 & -19.932 \\
\hline
\end{tabular}

Table 4. Summary of variations in reflection coefficient and frequency bands due to $\mathrm{rad}_{4}$

\begin{tabular}{lllllll}
\hline $\operatorname{rad}_{4}(\mathrm{~mm})$ & $\mathrm{f}_{1}(\mathrm{GHz})$ & $\mathrm{S}_{11}$ at $\mathrm{f}_{1}$ & $\mathrm{f}_{2}(\mathrm{GHz})$ & $\mathrm{S}_{11}$ at $\mathrm{f}_{2}$ & $\mathrm{f}_{3}(\mathrm{GHz})$ & $\mathrm{S}_{11}$ at $\mathrm{f}_{3}$ \\
\hline 4.5 & 1.5884 & -14.690 & 2.6132 & -13.629 & 3.892 & -17.829 \\
5.5 & 1.5884 & -21.927 & 2.6321 & -24.969 & 3.739 & -34.331 \\
6.5 & 1.576 & -29.691 & 2.668 & -22.084 & 3.636 & -26.765 \\
7.5 & 1.555 & -28.788 & 2.717 & -17.607 & 3.5786 & -26.721 \\
8.5 & 1.4591 & -2.585 & 2.578 & -30.310 & 2.943 & -5.871 \\
9.5 & 1.4862 & -21.418 & 2.899 & -25.189 & 3.5566 & -9.949 \\
\hline
\end{tabular}

Table 5. Summary of variations in reflection coefficient and frequency bands due to $l_{1}$

\begin{tabular}{lllllll}
\hline$l_{1}(\mathrm{~mm})$ & $\mathrm{f}_{1}(\mathrm{GHz})$ & $\mathrm{S}_{11}$ at $\mathrm{f}_{1}$ & $\mathrm{f}_{2}(\mathrm{GHz})$ & $\mathrm{S}_{11}$ at $\mathrm{f}_{2}$ & $\mathrm{f}_{3}(\mathrm{GHz})$ & $\mathrm{S}_{11}$ at $\mathrm{f}_{3}$ \\
\hline 3 & 1.675 & -19.701 & 2.794 & -19.330 & 3.6872 & -18.165 \\
4 & 1.6211 & -23.959 & 2.731 & -42.076 & 3.6492 & -30.696 \\
5 & 1.576 & -29.691 & 2.668 & -22.084 & 3.636 & -26.765 \\
6 & 1.534 & -24.593 & 2.618 & -15.879 & 3.6235 & -21.327 \\
7 & 1.4889 & -17.005 & 2.569 & -12.078 & 3.598 & -18.947 \\
8 & 1.8106 & -0.781 & 2.712 & -5.962 & 3.586 & -12.160 \\
\hline
\end{tabular}

Table 6. Summary of performance factors

\begin{tabular}{llll}
\hline \multicolumn{1}{c}{ Parameters } & $\mathrm{f}_{1}=1.576 \mathrm{GHz}$ & $\mathrm{f}_{2}=2.668 \mathrm{GHz}$ & $\mathrm{f}_{3}=3.636 \mathrm{GHz}$ \\
\hline Gain $(d B)$ & 1.63 & 2.59 & 3.23 \\
VSWR & 1.067 & 1.170 & 1.096 \\
Beamwidth $(\mathrm{Deg})$ & 88.1 & 56.9 & 26.2 \\
Bandwidth $(\mathrm{MHz})$ & 21.1 & 72.2 & 98.9 \\
Radiation efficiency $(\%)$ & 70.11 & 76.34 & 72.1 \\
\hline
\end{tabular}




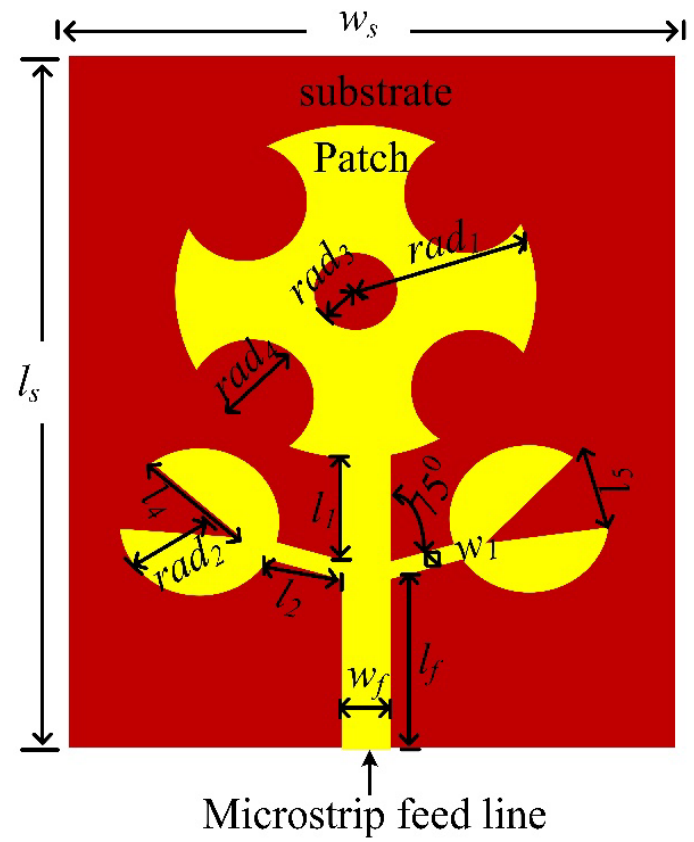

(a)

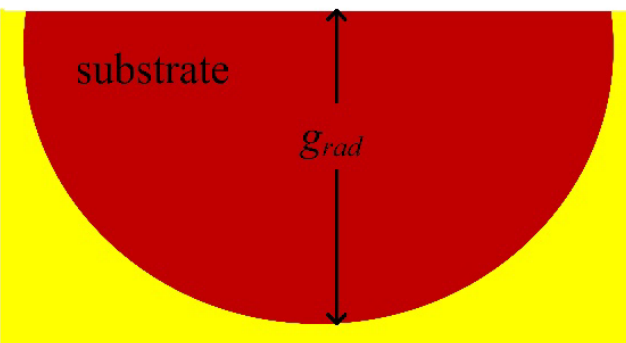

Ground plane

Figure 1. Geometrical model of proposed flower-shaped monopole antenna (a) Front view (b) Back view
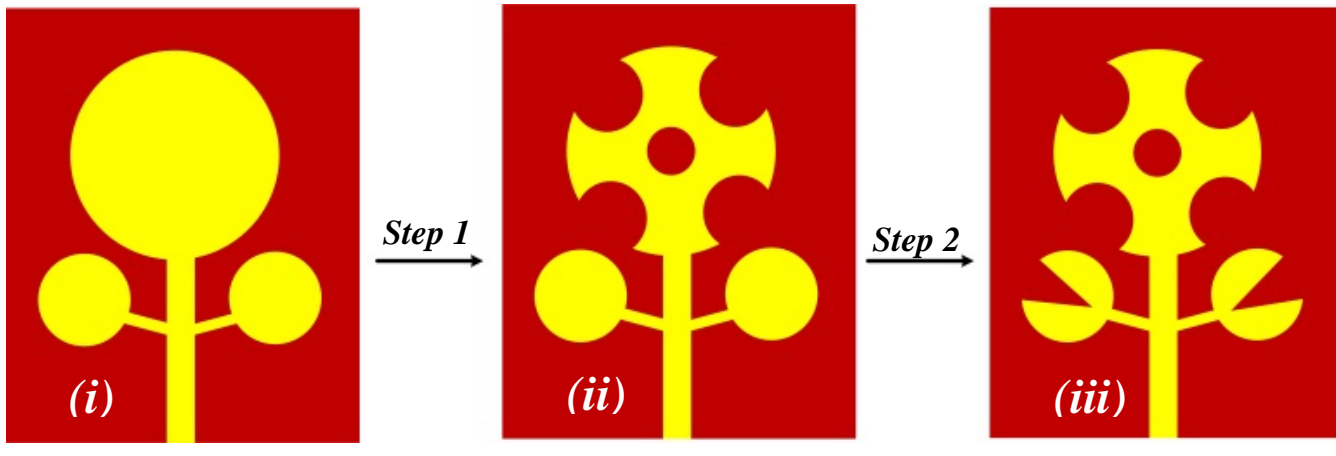

(a)

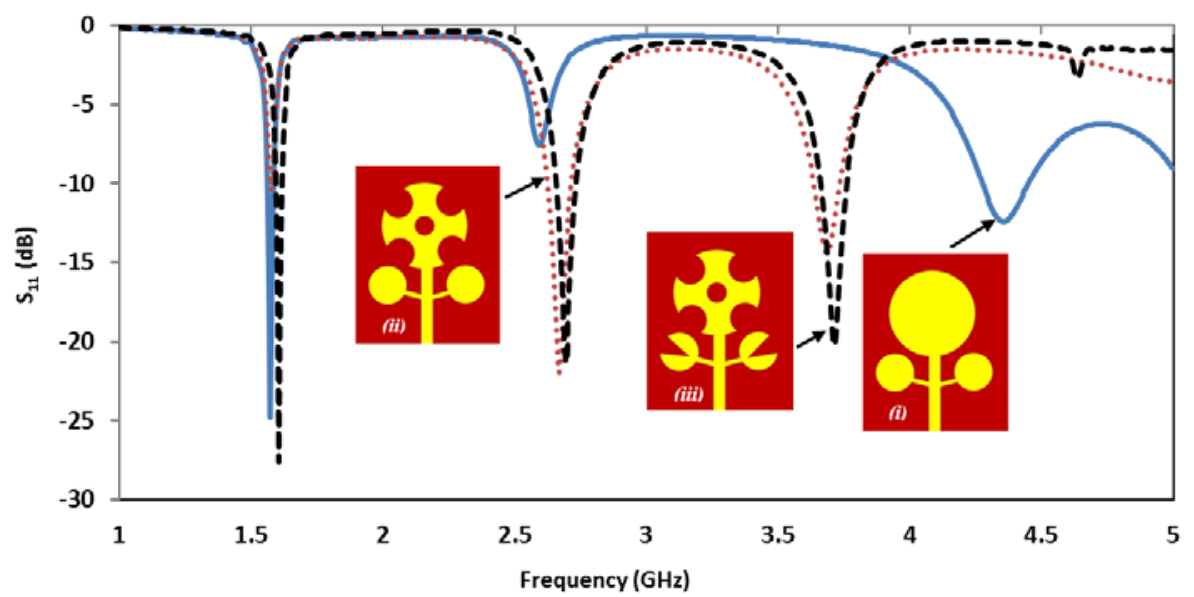

(b) 


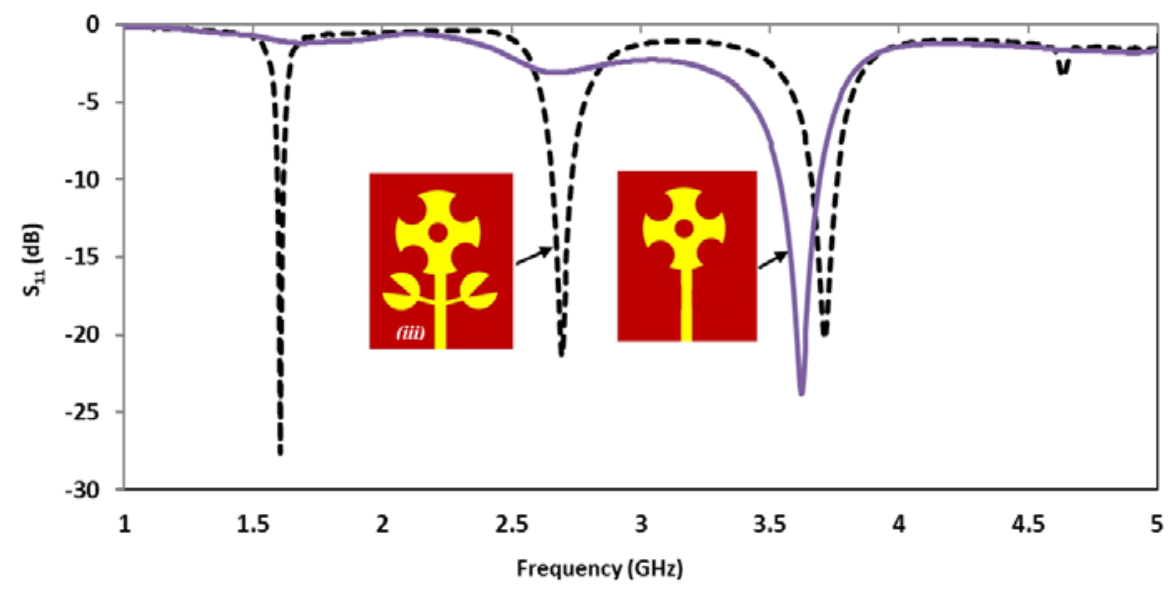

(c)

Figure 2. Geometry and reflection coefficient of the proposed flower-shaped monopole antenna (a) design steps (b) comparison of s-parameters for these design steps (c) comparison of the sparameters of the proposed antenna with and without the branches

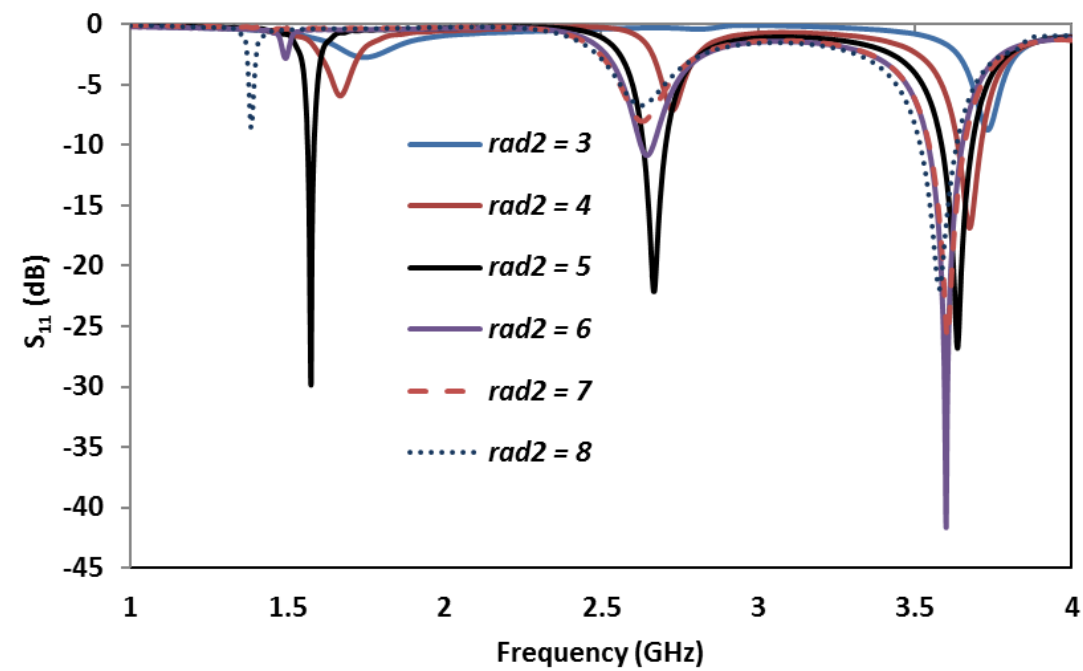

Figure 3. Reflection coefficient and resonant frequency variations due to $\operatorname{rad}_{2}$

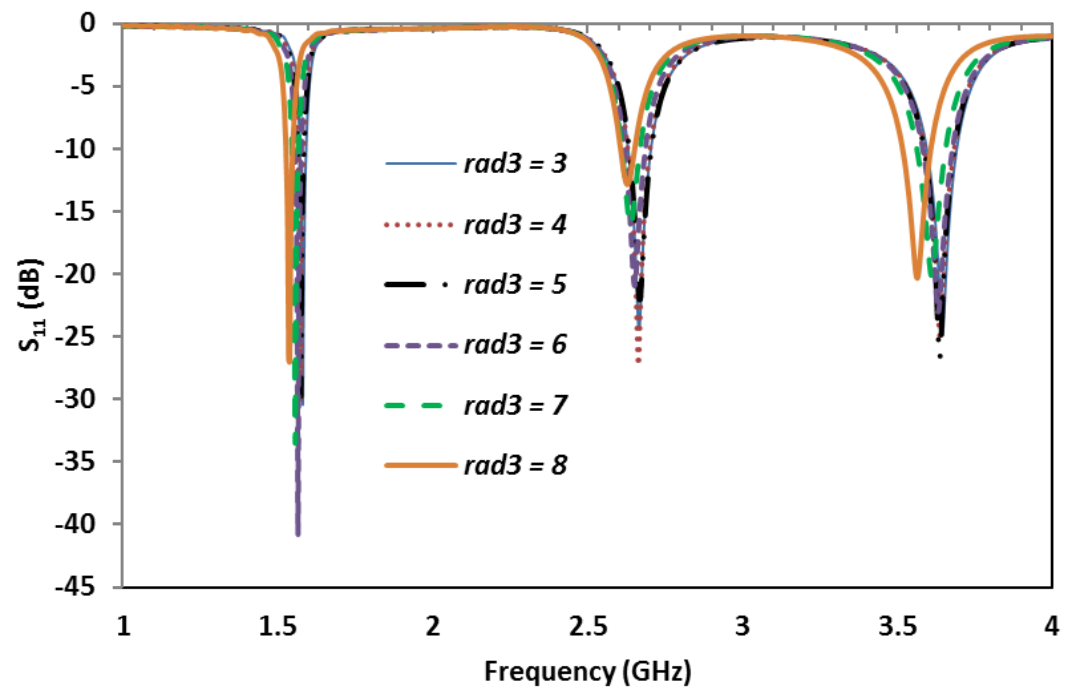

Figure 4. Reflection coefficient and frequencies variations due to $\operatorname{rad}_{3}$ 


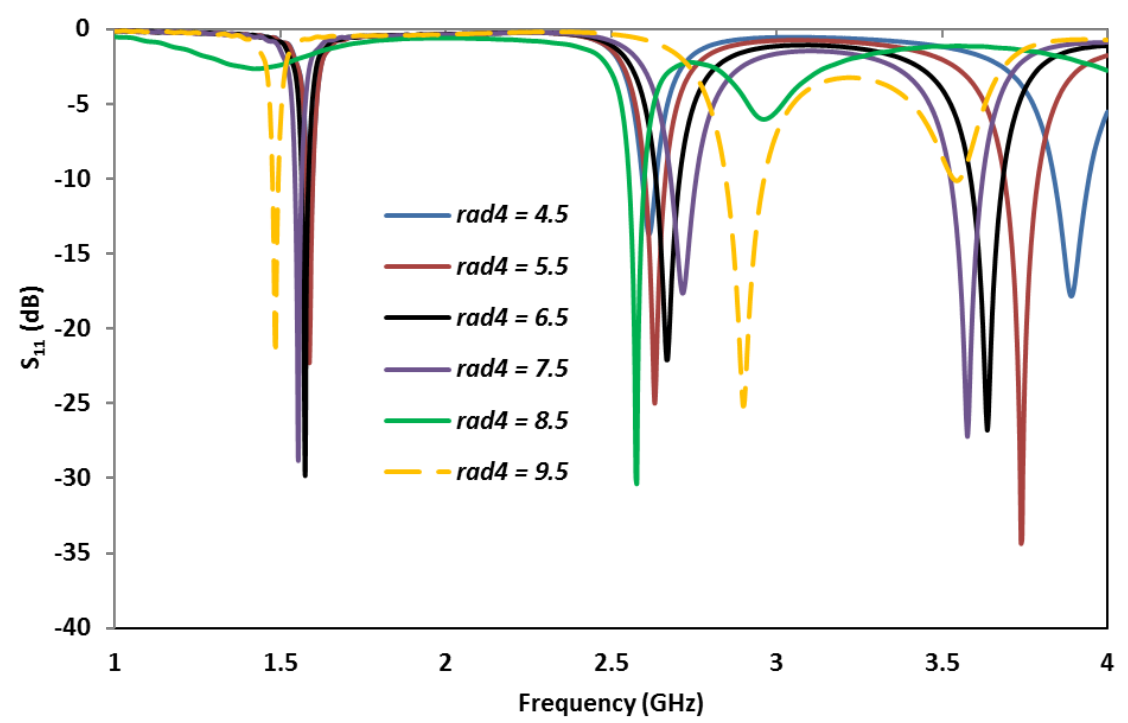

Figure 5. Reflection coefficient and frequency variations due to $\operatorname{rad}_{4}$

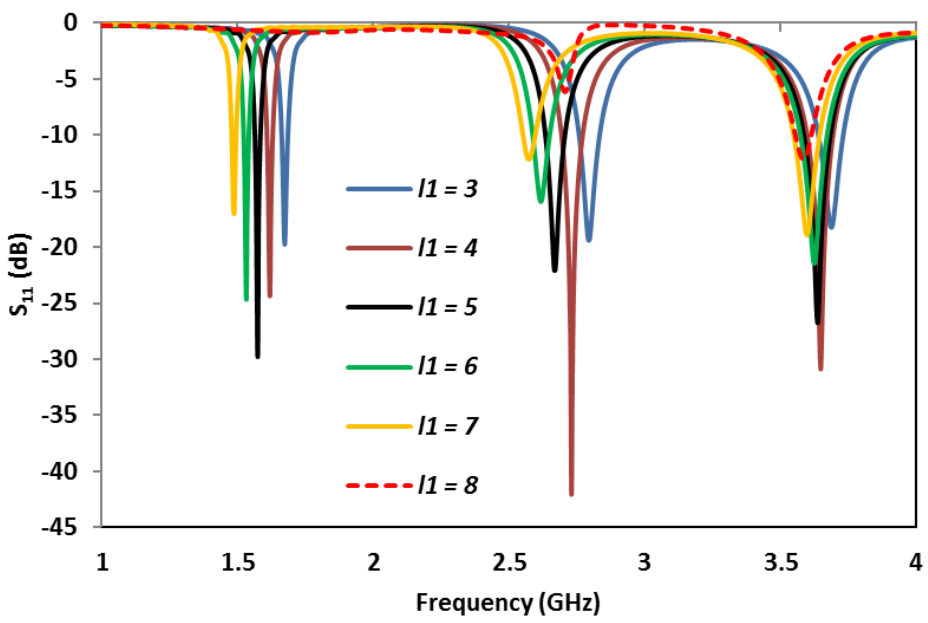

Figure 6. Variation in reflection coefficient and frequency bands due to changes in $l_{1}$

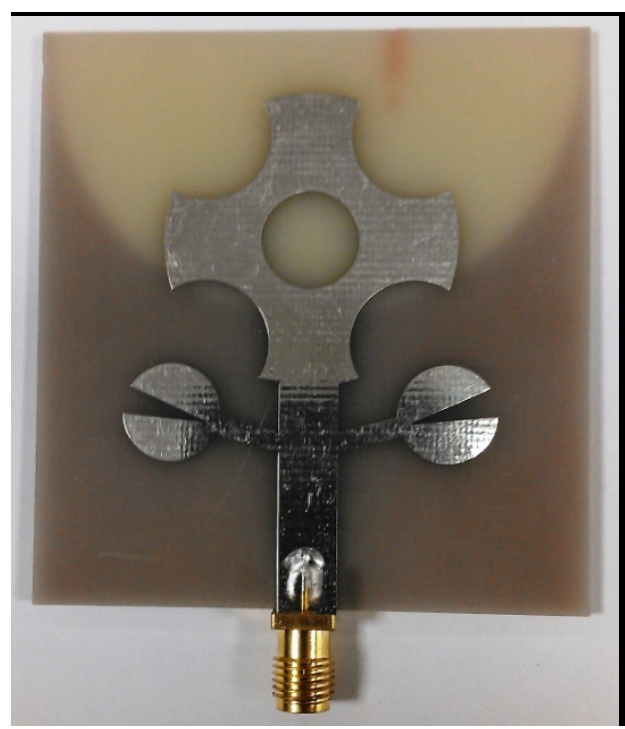

(a)

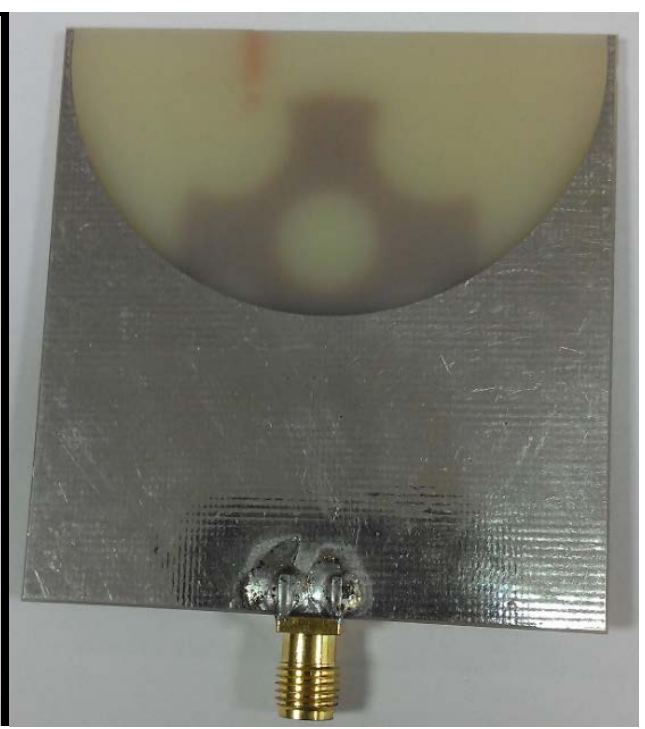

(b)

Figure 7. Fabricated flower shape antenna (a) Front view (b) Rear view 


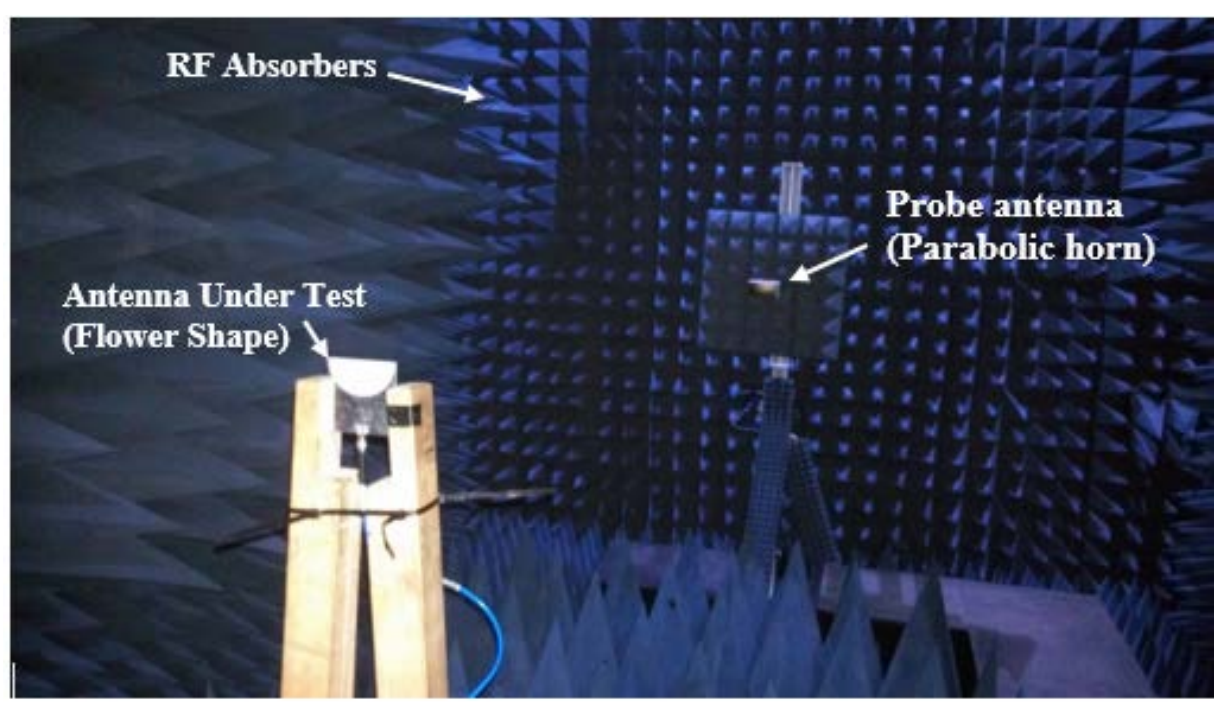

Figure 8. Measurement setup in anechoic chamber (NUST, Islamabad)

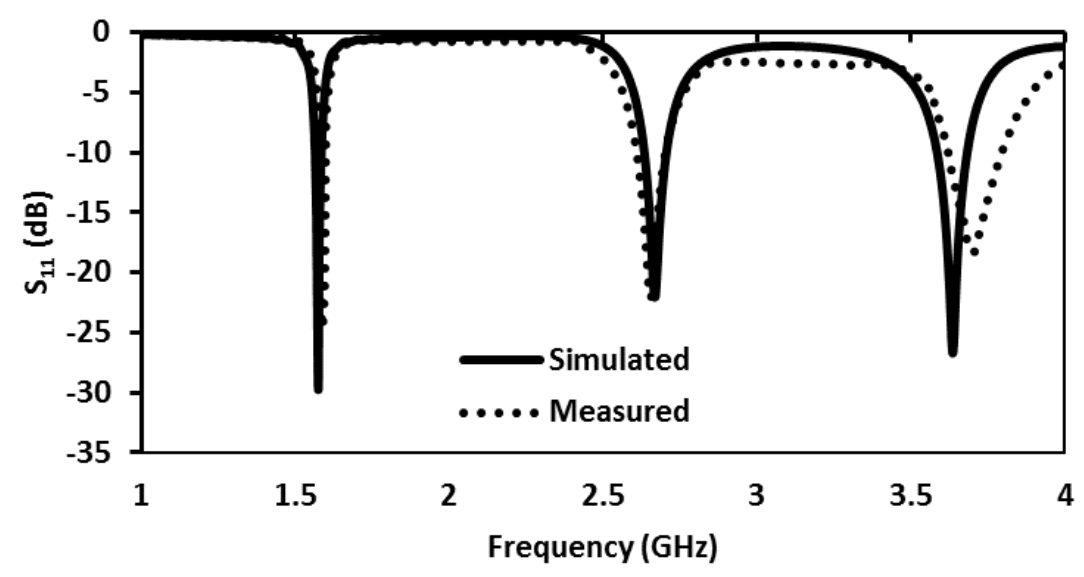

Figure 9. Simulated and measured reflection coefficient

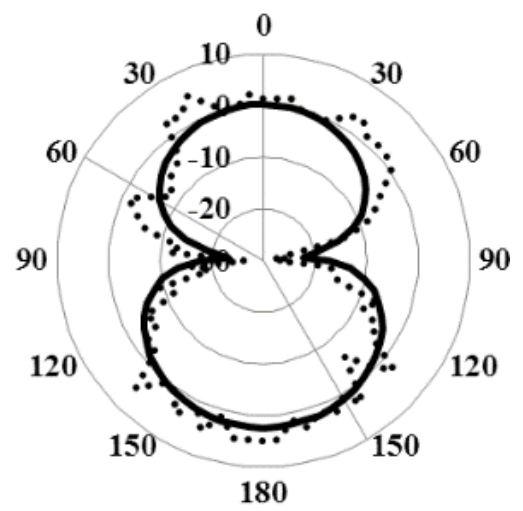

- Simulated $\cdots . .$. Measured

E-plane

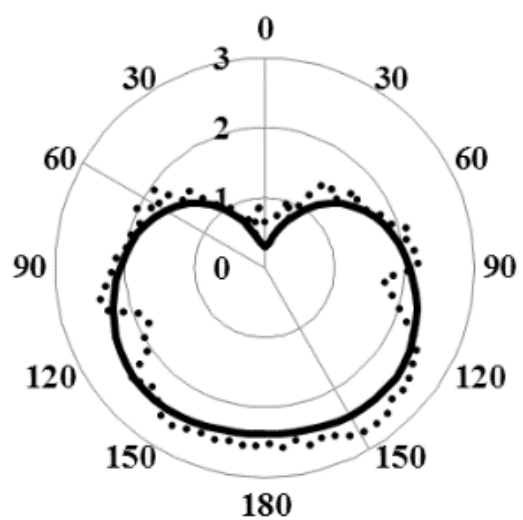

- Simulated $\cdots \cdots \cdot$ Measured

H-plane

(a) 


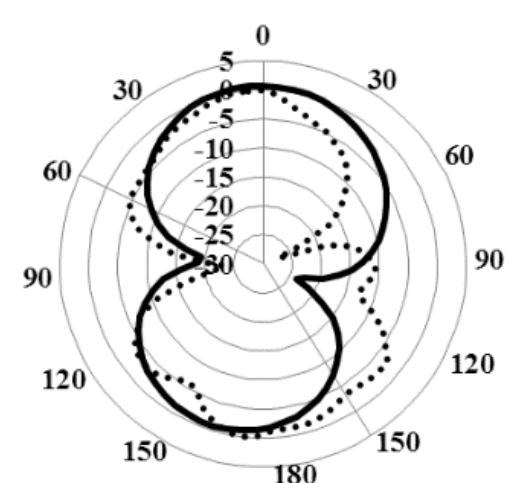

- Simulated $\cdots \cdot \cdot \cdot$ Measured

E-plane
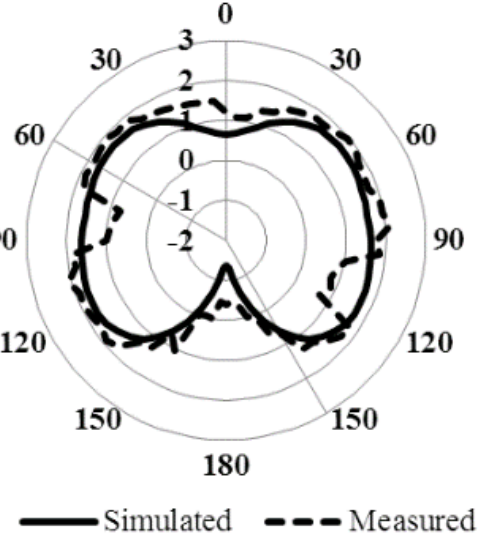

H-plane

(b)

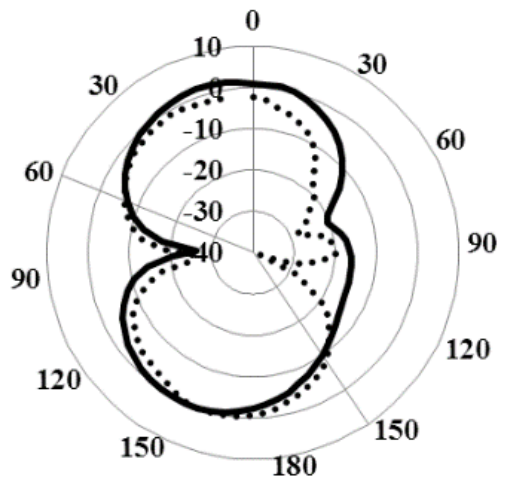

- Simulated $\cdots \cdot \cdot \cdot$ Measured

E-plane

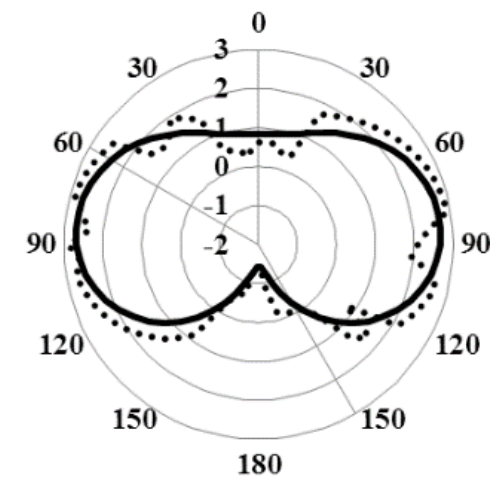

$\longrightarrow$ Simulated $\cdots \cdot \cdot \cdot$ Measured

H-plane

(c)

Figure 10. Comparison of simulated and measured gain (a) $1.576 \mathrm{GHz}$ (b) $2.668 \mathrm{GHz}$ (c) $3.636 \mathrm{GHz}$

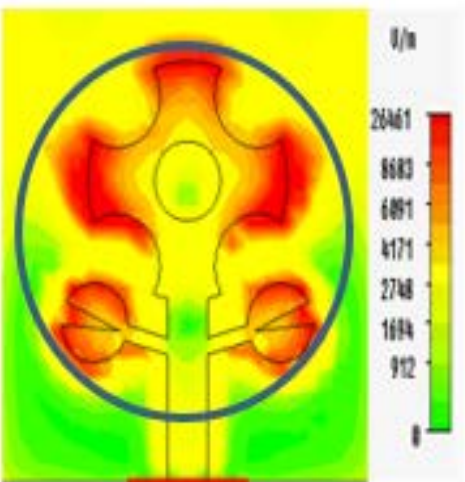

(a)

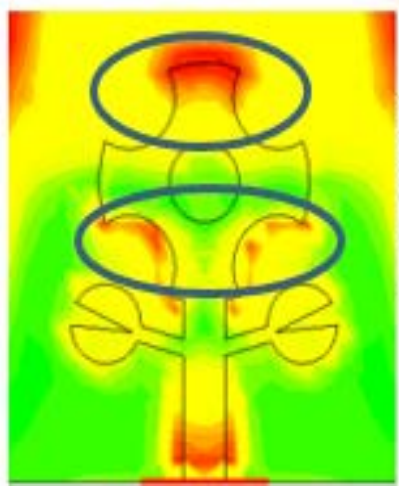

(b)
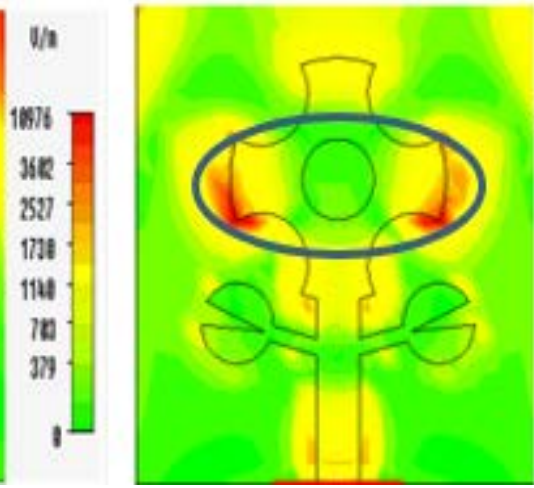

(c)

Figure 11. Surface electric field plots of the proposed antenna at various frequencies (a) 1.576 GHz (b) $2.668 \mathrm{GHz}$ (c) $3.636 \mathrm{GHz}$ 


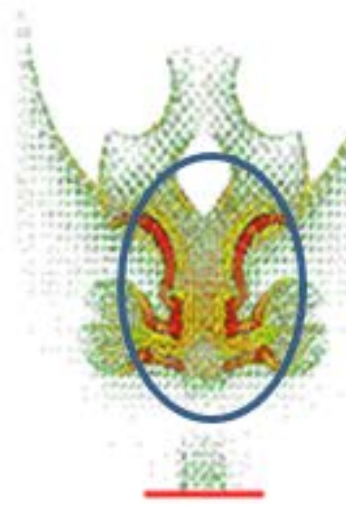

( a )

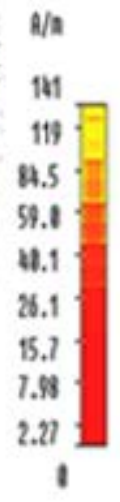

1

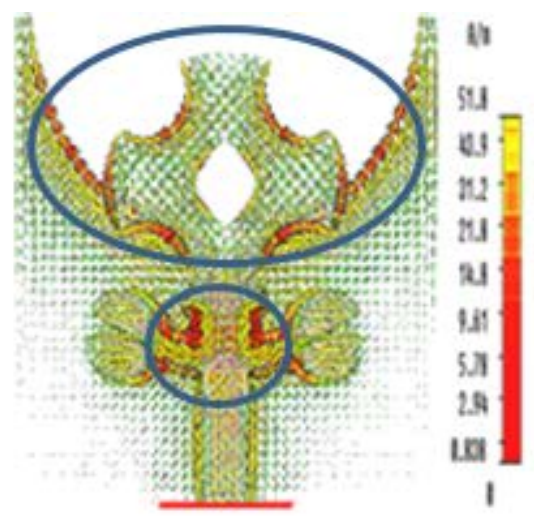

(b)

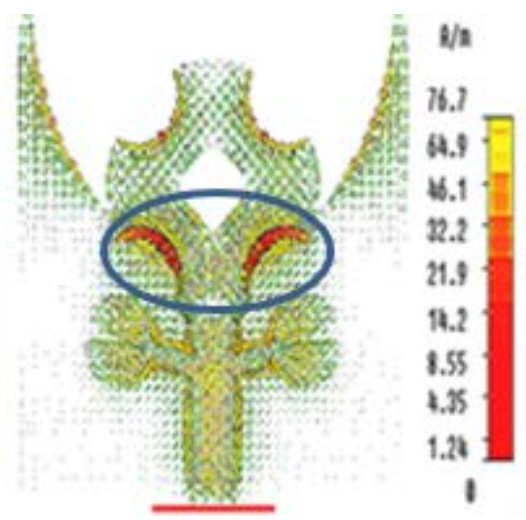

(c)

Figure 12. Surface current plots of the proposed antenna at various frequencies (a) $1.576 \mathrm{GHz}$ (b) $2.668 \mathrm{GHz}$ (c) $3.636 \mathrm{GHz}$ 